\title{
Crystallization Behavior of Palm Kernel Oil Monitored by In-Situ Focused Beam Reflectance Measurement (FBRM) and Particles Video Microscope (PVM) during Suspension Crystallization
}

\author{
Leping Dang1, Shuai $\mathrm{Li}^{1}$, Hong Zhang2 ${ }^{2}$ Yaobin $\mathrm{Si}^{2}$, Zhanzhong Wang ${ }^{*}$ \\ ${ }^{1}$ School of Chemical Engineering and Technology, Tianjin University, Tianjin, China \\ ${ }^{2}$ Wilmar Biotechnology Research \& Development Center Co., Ltd., Shanghai, China \\ Email: ${ }^{*}$ wzz7698@tju.edu.cn
}

Received 21 November 2014; accepted 6 January 2015; published 16 January 2015

Copyright (C) 2015 by authors and Scientific Research Publishing Inc.

This work is licensed under the Creative Commons Attribution International License (CC BY).

http://creativecommons.org/licenses/by/4.0/

\section{(c) (i) Open Access}

\begin{abstract}
Crystallization behavior and kinetics study of palm kernel oil (PKO) were investigated using differential scanning calorimetry (DSC) by controlling cooling and reheating rate within a certain range of temperature. The evolution of morphology and particle counts was analyzed by focused beam reflectance measurement (FBRM) and particles video microscope (PVM) at the nucleation stage during suspension crystallization. The particle counts and morphological evolution from needle-like aggregations to amorphous form from PVM were observed during the initial crystallization stage, which meant that a phase transition was likely to occur. This work can give a better understanding of complicated fat system crystallization behavior and provide some critical instructions to control fractionation process.
\end{abstract}

Keywords

Palm Kernel Oil, Crystallization Behavior, Crystal Morphology, In-Situ Analysis

\section{Introduction}

Palm kernel oil (PKO) is a very important vegetable oil in world trade. The oil and its fat derivatives that have ${ }^{*}$ Corresponding author.

How to cite this paper: Dang, L.P., Li, S., Zhang, H., Si, Y.B. and Wang, Z.Z. (2015) Crystallization Behavior of Palm Kernel Oil Monitored by In-Situ Focused Beam Reflectance Measurement (FBRM) and Particles Video Microscope (PVM) during Suspension Crystallization. Advances in Materials Physics and Chemistry, 5, 31-38. http://dx.doi.org/10.4236/ampc.2015.51005 
been processed are used to make food stuff in a wide range. PKO is a relatively firm at room temperature while it melts quickly and cleanly at about $50^{\circ} \mathrm{C}$. $\mathrm{PKO}$, divided into palm kernel olein and palm kernel stearin, is all complex mixtures of various triglycerides (TGs), and the TG comes from esterification of three fatty acids with glycerol. Melting suspension crystallization, or so called "dry fractionation”, is generally used in food industry in order to broaden the fats' use. The processed fats can often take place other oils and fats in industrial production. In this process, TGs with higher melting point will crystallize out as a solid fractionation at specific temperature, which is called stearin (PKST), while the lower melting point TGs will still present a liquid form called olein (PKOL). Meanwhile, PKO will resolve into stearin and olein by crystallization. Therefore, the research on the crystallization behavior and kinetics of PKO is of great importance for the process control and optimization.

Some published works relating to other fats, such as palm oil, coconut oil and milk fat, are mainly concerned with crystallization methods, crystallization process, kinetics and fraction properties, and so on [1] [2]. Investigations of crystallization behavior and kinetics of PKO are relatively rare. In this work, DSC was used to analyze the crystallization kinetics data of PKO. FBRM and PVM are well-established in-situ techniques for characterizing and quantifying changes in crystallization processes. In this work, in-situ FBRM and PVM are used to assist to study crystallization behavior, which provides more direct experimental analysis and is helpful for understanding the crystal growth mechanism of fats.

\section{Materials and Methods}

\subsection{Materials}

PKO was provided by Wilmar (Shanghai) Biotechnology Research \& Development Center Co., Ltd.) with iodine value (IV) 18.8, respectively. All other reagents and solvents were of analytical or chromatographic grade purchased from Kewei Chemical Reagent Co. Ltd. (Tianjin, China). The XRD patterns of PKO and PKST/ PKOL separated by suspension crystallization is illustrated in Figure 1. XRD Analyses were performed using a Rigaku D/max-2500 X-ray powder diffractometer with $\mathrm{CuK} \alpha$ radiation $(\lambda=1.54 \AA)$, a tube voltage of $40 \mathrm{kV}$, and a tube current of $100 \mathrm{~mA}$ to collect the XRD patterns of the blends samples with different PKST/PKOL proportion preserved in $-4^{\circ} \mathrm{C}$ in refrigerator. Data were collected from $5^{\circ}$ to $35^{\circ}$ at a continuous scan rate of 1.2 deg $\min ^{-1}$.

\subsection{Crystallization Behavior by DSC}

Crystallization kinetics was determined using DSC by the described method [3] [4]. Percent conversion as a function of time was determined using Mettler Toledo DSC 1 with thermal analysis software Mettler Stare. All the samples were accurately weighed ( 6 - $9 \mathrm{mg}$ ) using an analytical balance (type XS105, Mettler Toledo) and initially heated at $60^{\circ} \mathrm{C}$ for $10 \mathrm{~min}$ in order to destroy crystal memories and then cooled at the rate of $10^{\circ} \mathrm{C} \cdot \mathrm{min}^{-1}$ to the preset temperature $\left(15^{\circ} \mathrm{C}, 17^{\circ} \mathrm{C}, 19^{\circ} \mathrm{C}, 21^{\circ} \mathrm{C}, 22^{\circ} \mathrm{C}, 23^{\circ} \mathrm{C}\right)$ and held 30 min at the present temperature for crystallization until no change in the heat flow recorded in the heat flow versus time plot. Subsequently, crystallographic thermograms were obtained. Fractions of crystals with time were calculated from the DSC profiles.

\subsection{On Line Crystallization Experiments Assisted by FBRM and PVM}

The in-situ FBRM and PVM are powerful tools that typically used for particle size and image tracing within the process environment. In this work, FBRM (Mettler Toledo) particle size measurements were complimented by an on-line process monitor system, to get the change of particle size and crystal behavior within Easymax (Mettler Toledo) as crystallizer. Solution was measured every $5 \mathrm{~s}$ with FBRM for counts in the 0 - 300 micron size range [5]. Particle Video Microscope was used to follow the morphology of the fat crystals or crystal clusters during the crystallization process [6].

\section{Results and Discussion}

\subsection{XRD Analysis}

Figure 1 illustrates the XRD patterns of PKO crystals. From Figure 1, it can be seen that some characteristic peaks in the XRD patterns appears at $2 \theta$ 7.74, 20.78 and 23.06. The XRD patterns indicate PKO crystals with the regular arrangements of specific TGs, which means molecular ordering in crystal lattice. 


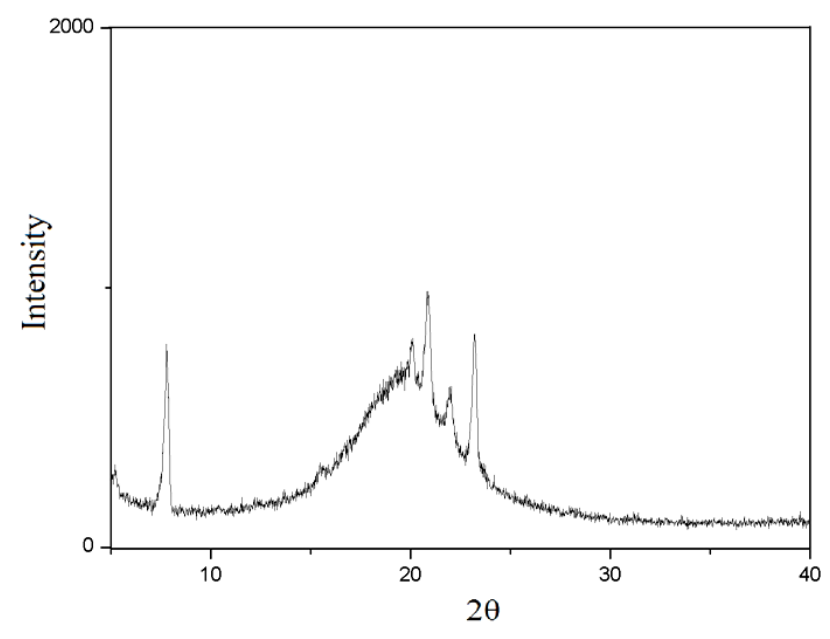

Figure 1. The XRD pattern of PKO crystals.

\subsection{Crystallization Behavior of PKO by DSC}

Figure 1 illustrates the XRD patterns of PKO crystals. From Figure 1, it can be seen that some characteristic peaks in the XRD patterns appears at $2 \theta 7.74,20.78$ and 23.06. The XRD pattern indicate PKO crystals with the regular arrangements of specific TGs, which means molecular ordering in crystal lattice.

The percent conversion in isothermal procedures was determined using DSC in this work. As the results shown in Figure 2, it can be seen that the fractions of crystals are drastically rose below $19^{\circ} \mathrm{C}$, while the fractions of crystals become slow above $21^{\circ} \mathrm{C}$ and fractions of crystals change slower with constant temperature increasing.

\subsection{Suspension Crystallization of PKO}

According to above crystallization behavior analysis by DSC, a trial of PKO suspension crystallization process was performed by in-situ FBRM and PVM. The in-situ experimental setup for suspension crystallization is shown in Figure 3. The different cooling conditions for batch suspension crystallization were shown as Figure 4.

\subsubsection{Crystallization Experiments in Cooling Curve 1}

Figure 5(a) showed that crystals counts with 0 - $10 \mu \mathrm{m}$ size drastically increase when the temperature approach $29^{\circ} \mathrm{C}$, which is an indicative of a population growth due to nucleation. In comparison, the increase of crystals counts with $10-50 \mu \mathrm{m}$ size is relative slow than $<10 \mu \mathrm{m}$ size and the counts with 50 - $150 \mu \mathrm{m}$ size mainly unchanged. The average particle size change detected by FBRM is shown in Figure 5(b). The average particle size gradually increases with crystallization proceeding and mean particle size relatively stable at 8 microns with large fluctuations. While there are obvious fluctuations on both the particles number and mean chord curves, which maybe because of the crystals' agglomeration and breakage.

Figure 6 shows that under the condition of fast cooling parameter, particles appear and rapidly grow to be aggregation. And after a period of time, the liquid change to turbidity fast. The agglomeration phenomenon of PKST crystals leads to the fluctuations in FBRM measured data and what' more, the serious liquid holding because of the agglomeration leads difficulty in the separation of PKOL and PKST. This may be the main reason that why PKO can't be well separated without compression and filtration.

\subsubsection{Crystallization Experiments in Cooling Curve 2}

Figure 7(a) showed that crystals counts with 0 - $50 \mu \mathrm{m}$ size drastically increase when the temperature approaches $28^{\circ} \mathrm{C}$, which is an indicative of a population growth due to nucleation. In comparison, the total number of particles was higher than fast cooling experiment especially the particles with $10-50 \mu \mathrm{m}$ size. And the counts with 50 - $150 \mu \mathrm{m}$ sizes were almost unchanged. The mean particle size change detected by FBRM is shown in Figure 7(b). The mean particle size gradually increased. With crystallization proceeding and mean particle size relatively stable at 9 microns with relatively small fluctuations. 


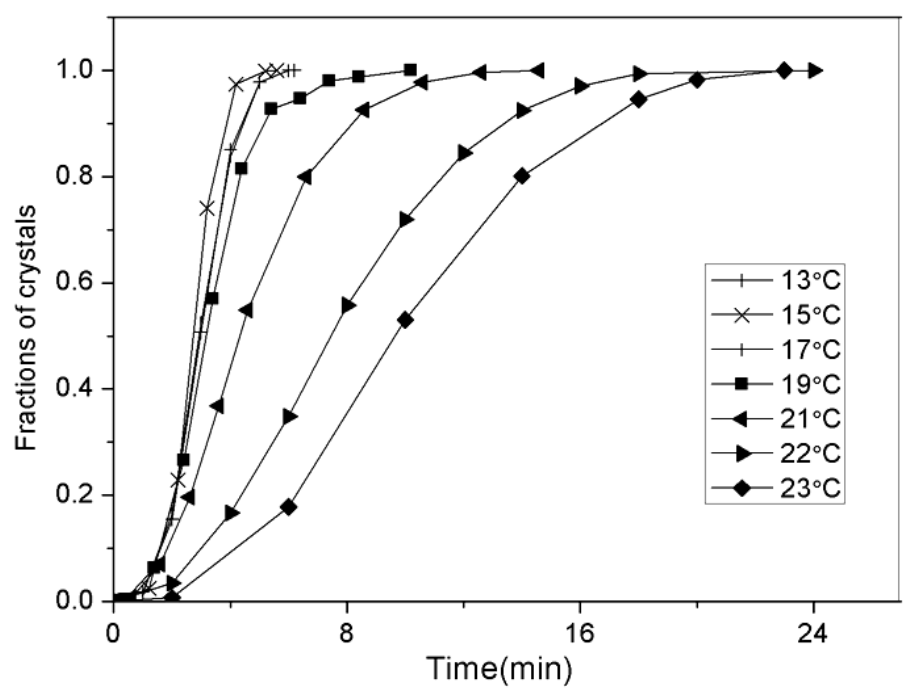

Figure 2. The fractions of crystals with time during isothermal crystallization.

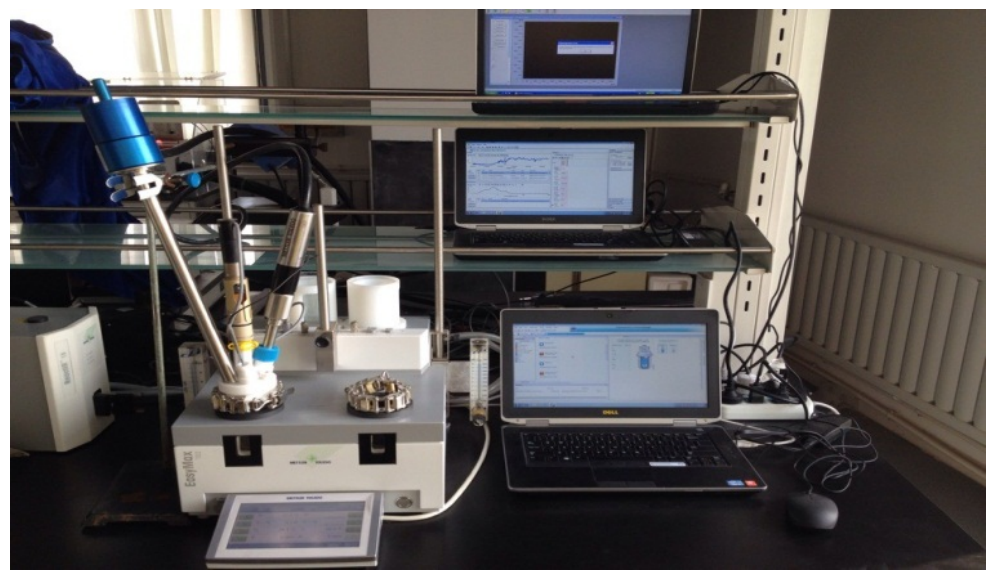

Figure 3. Apparatus of in-situ FBRM and PVM experiments.

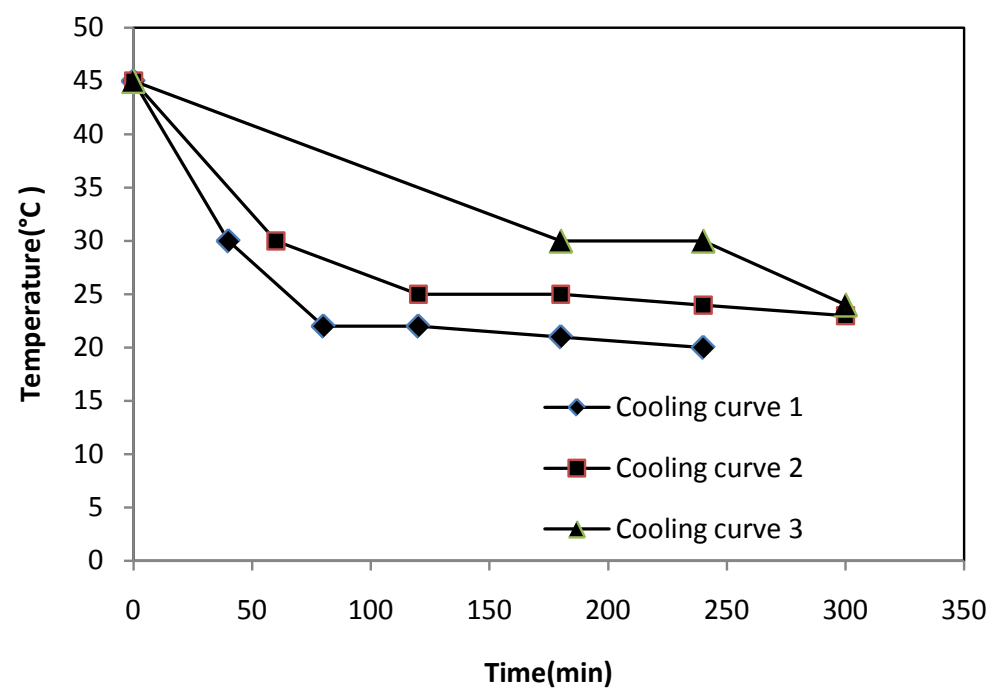

Figure 4. The cooling curves of PKO during suspension crystallization. 


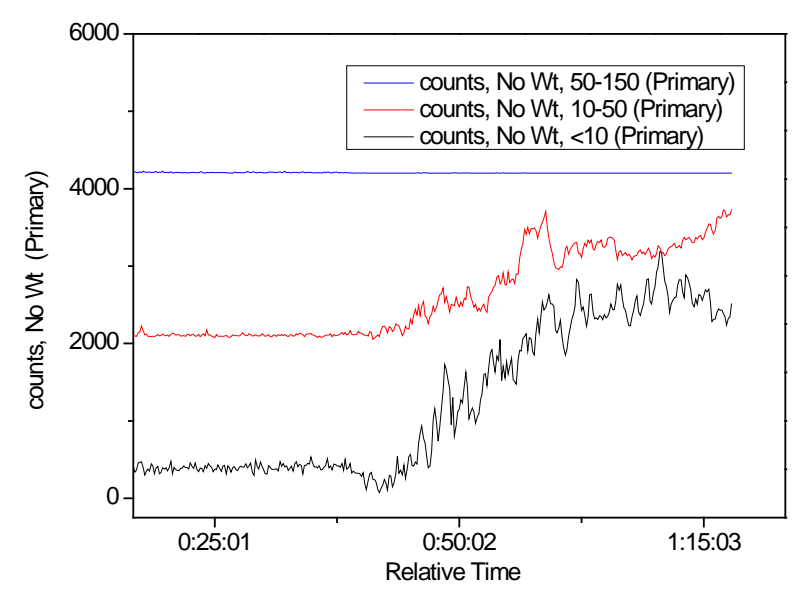

(a)

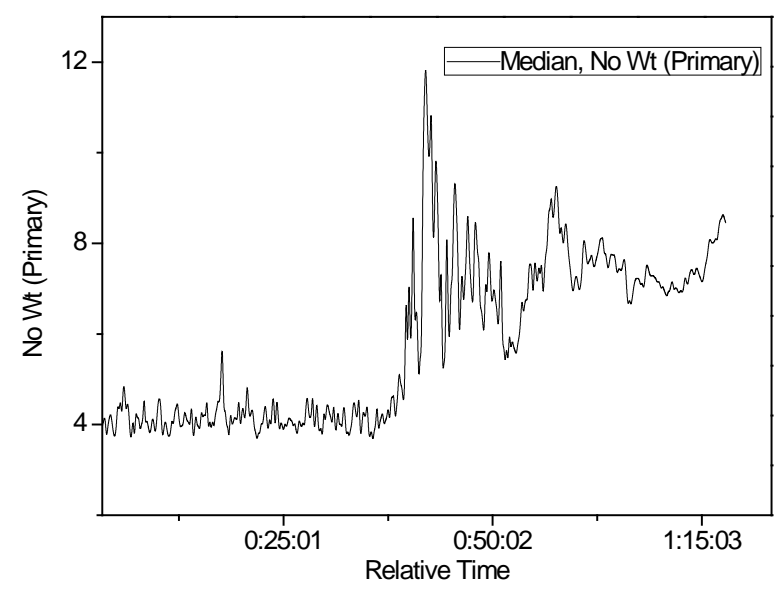

(b)

Figure 5. The change of different particle sizes (a) and average particle size (b) of PKO with time.

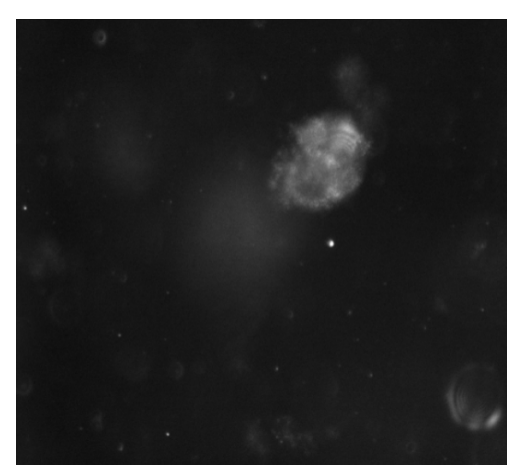

(a)

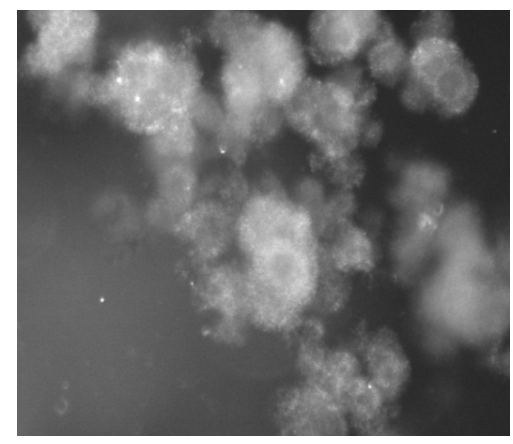

(c)

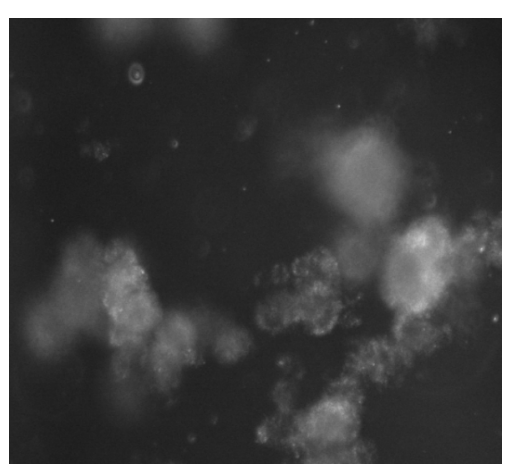

(b)

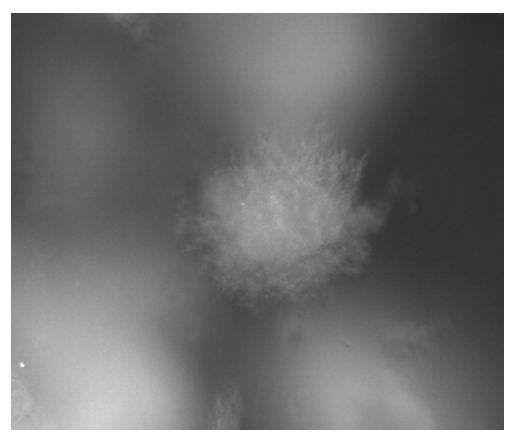

(d)

Figure 6. PVM images at different temperatures (a) $29^{\circ} \mathrm{C}$; (b) $28^{\circ} \mathrm{C}$; (c) $25^{\circ} \mathrm{C}$; (d) $24^{\circ} \mathrm{C}$ with changing time.

Figure 8 shows that initial crystal nucleus are needle-like crystals, with the increasing of particle number, the min crystals begin to agglomerate consequently form clouds-like morphology. And these graphics also traced the changing process of PKO particle morphology.

\subsubsection{Crystallization Experiments in Cooling Curve 3}

Figure 9(a) showed that crystals counts with 0 - $50 \mu \mathrm{m}$ size drastically increase at $28^{\circ} \mathrm{C}$, which is an indicative of a population growth due to nucleation. And it is noteworthy that the counts of $10-50 \mu \mathrm{m}$ size particles were almost equivalent to 0 - $10 \mu \mathrm{m}$ size particle. To some degree, the counts of $50-150 \mu \mathrm{m}$ size particles were increased which was not to be found in the two fomer experiments. The average particle size change detected by FBRM is shown in Figure 9(b). The average particle size gradually increases with crystallization proceeding. 


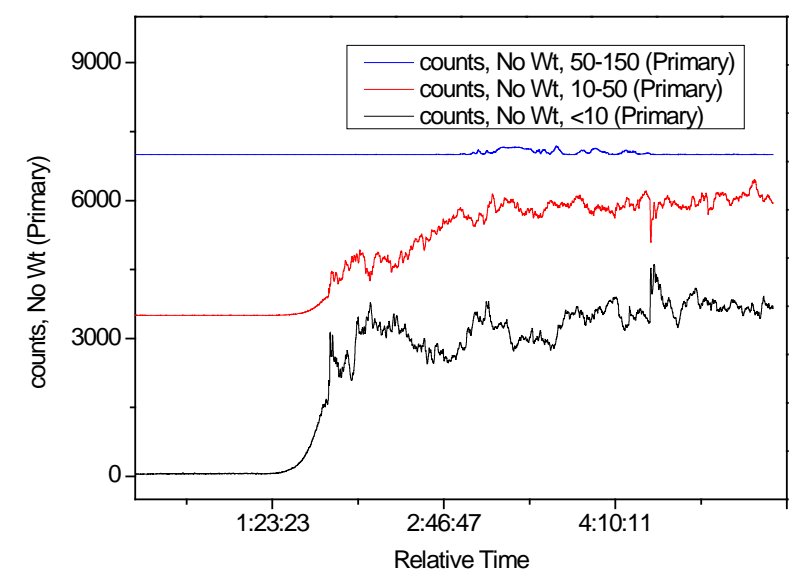

(a)

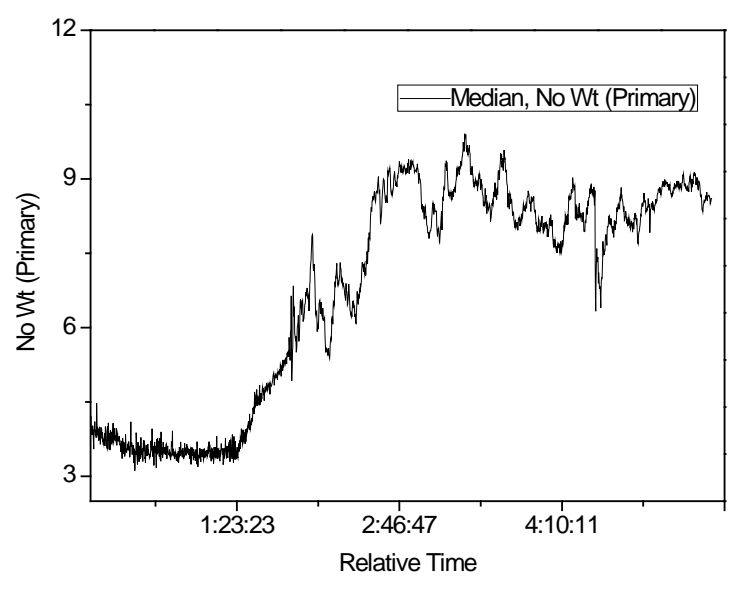

(b)

Figure 7. The change of different particle sizes and average particle size of PKO with time.

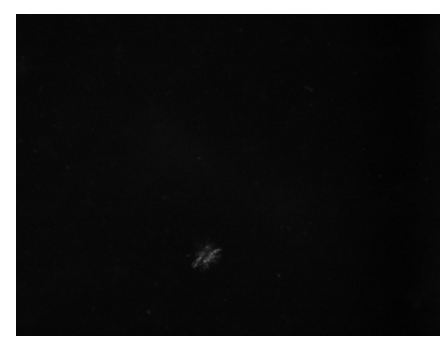

(a)

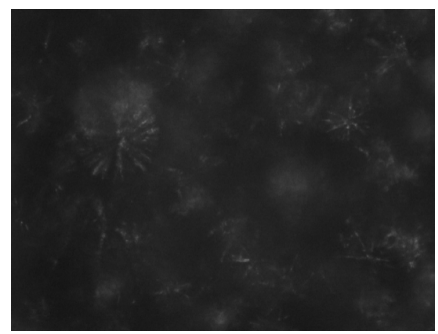

(c)

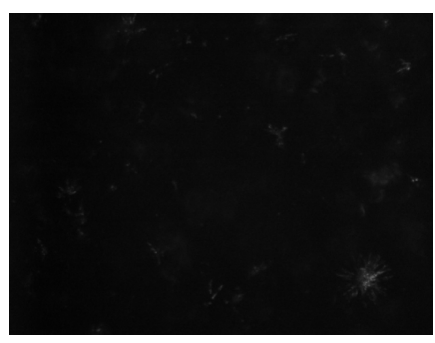

(b)

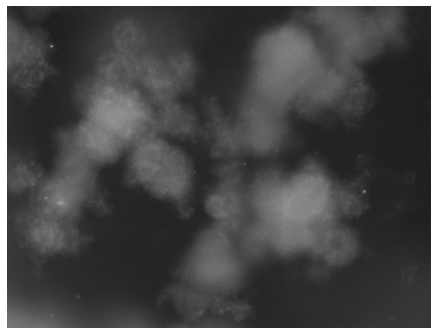

(d)

Figure 8. PVM images at different temperatures (a) $28^{\circ} \mathrm{C}$; (b) $26^{\circ} \mathrm{C}$; (c) $25^{\circ} \mathrm{C}$; (d) $24^{\circ} \mathrm{C}$.

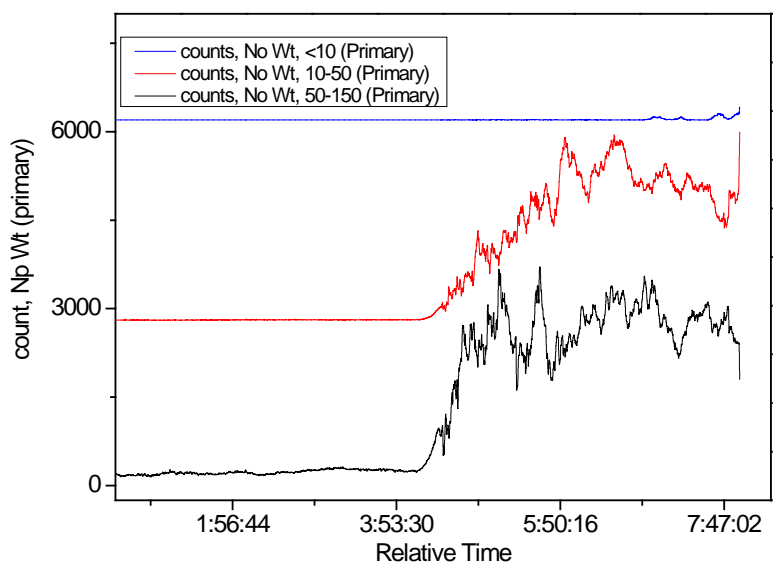

(a)

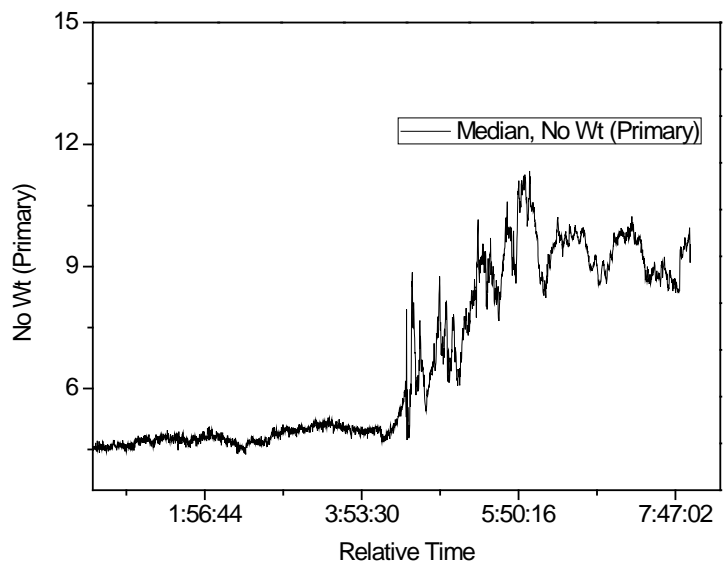

(b)

Figure 9. The change of different particle sizes and average particle size of PKO with time. 


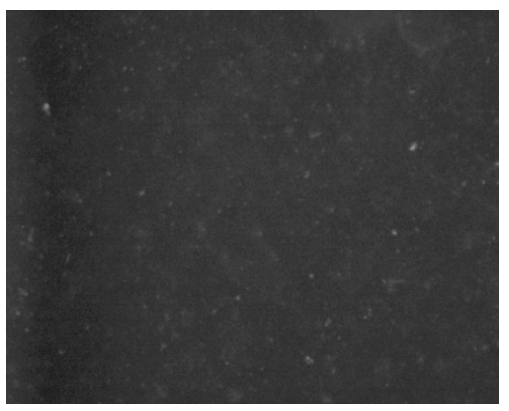

(a)

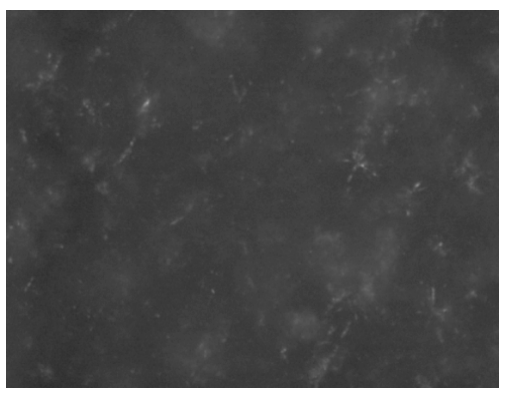

(c)

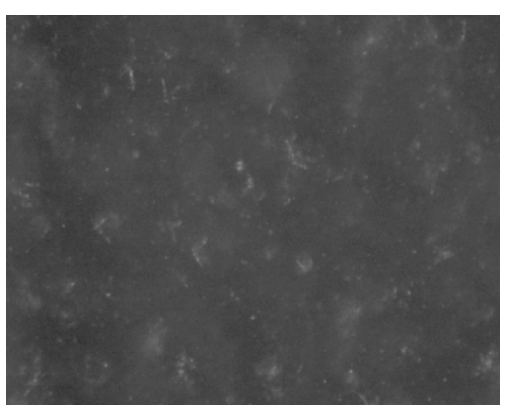

(b)

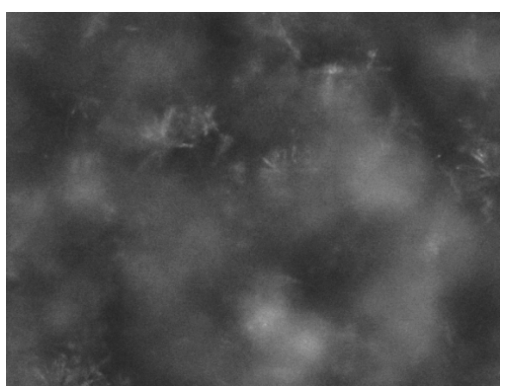

(d)

Figure 10. PVM images at different temperatures (a) $28^{\circ} \mathrm{C}$; (b) $24.5^{\circ} \mathrm{C}$; (c) $24.4^{\circ} \mathrm{C}$; (d) $24^{\circ} \mathrm{C}$.

With crystallization proceeding and mean particle size relatively stable at 10 microns with relatively small fluctuations.

Figure 10 also shows that initial crystal nucleus are needle-like crystals, with the increasing of particle number, the min crystals begin to agglomerate consequently form clouds-like morphology.

\section{Conclusion}

In this study, the crystallization behavior of palm kernel oil was analyzed. The DSC study indicates that the crystallization temperature plays an important role in the process of suspension crystallization. The suspension crystallization trials monitored by in-situ FBRM and PVM under different cooling conditions show that the PKO crystals will agglomerate seriously to form flocculent morphology at the initial crystallization stage. With the increase of cooling rate, the mean particle size decreases, which means that the cooling rate plays an important role in the aspects of PKO nucleation, growth and the revolution of morphology. The agglomeration of crystals may result in liquid holding in crystals, which can lead to poor separation of PKOL and PKST.

\section{Acknowledgements}

We are grateful to Wilmar (Shanghai) Biotechnology Research \& Development Center Co., Ltd. for the financial support.

\section{References}

[1] Chaleepa, K., Szepes, A. and Ulrich, J. (2010) Dry Fractionation of Coconut Oil by Melt Crystallization. Chemical Engineering Research and Design, 88, 1217-1222. http://dx.doi.org/10.1016/j.cherd.2010.01.026

[2] Zaliha, O., Chong, C.L., Cheow, C.S., Norizzah, A.R. and Kellens, M.J. (2004) Crystallization Properties of Palm Oil by Dry Fractionation. Food Chemistry, 86, 245-250. http://dx.doi.org/10.1016/j.foodchem.2003.09.032

[3] Meng, Z., et al. (2011) Comparative Analysis of Lipid Composition and Thermal, Polymorphic, and Crystallization Behaviors of Granular Crystals Formed in Beef Tallow and Palm Oil. Journal of Agricultural and Food Chemistry, 59, 1432-1441. http://dx.doi.org/10.1021/jf103875f

[4] Saberi, A.H., Lai, O.-M. and Toro-Vázquez, J.F. (2011) Crystallization Kinetics of Palm Oil in Blends with PalmBased Diacylglycerol. Food Research International, 44, 425-435. http://dx.doi.org/10.1016/j.foodres.2010.09.029 
[5] Hu, X.H., Cunningham, J.C. and Winstead, D. (2008) Study Growth Kinetics in Fluidized Bed Granulation with AtLine FBRM. International Journal of Pharmaceutics, 347, 54-61. http://dx.doi.org/10.1016/j.ijpharm.2007.06.043

[6] Kougoulos, E., Jones, A.G., Jennings, K.H. and Wood-Kaczmarc, M.W. (2005) Use of Focused Beam Reflectance Measurement (FBRM) and Process Video Imaging (PVI) in a Modified Mixed Suspension Mixed Product Removal (MSMPR) Cooling Crystallizer. Journal of Crystal Growth, 273, 529-534. http://dx.doi.org/10.1016/j.jcrysgro.2004.09.032 
Scientific Research Publishing (SCIRP) is one of the largest Open Access journal publishers. It is currently publishing more than 200 open access, online, peer-reviewed journals covering a wide range of academic disciplines. SCIRP serves the worldwide academic communities and contributes to the progress and application of science with its publication.

Other selected journals from SCIRP are listed as below. Submit your manuscript to us via either submit@scirp.org or Online Submission Portal.
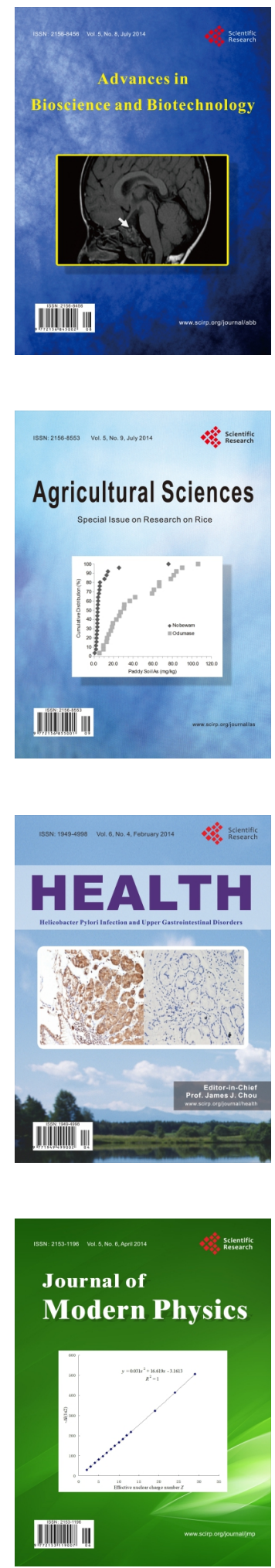
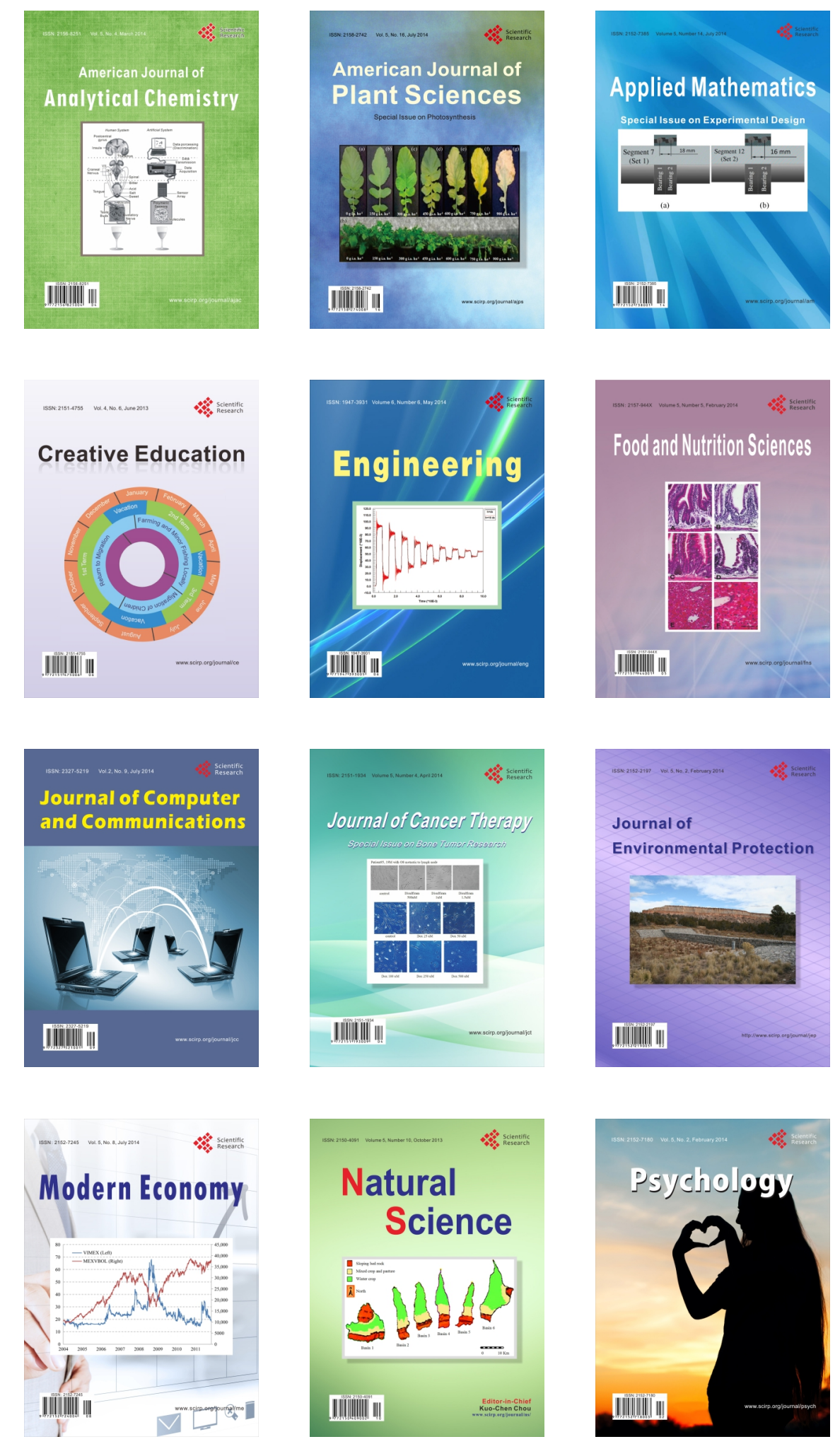